\title{
PENURUNAN TINGKAT STRES KERJA PADA PENERBANG MILITER MELALUI PENERAPAN TERAPI YOGA TAWA
}

\author{
Anggun Resdasari Prasetyo, Harlina Nurtjahjanti, Nailul Fauziah, Erin Ratna Kustanti
}

Fakultas Psikologi Universitas Diponegoro

J1. Prof. Soedharto SH Tembalang Semarang

anggun.resdasari@gmail.com

\begin{abstract}
The laughter yoga therapy is a physical exercise technique that combines yoga breathing techniques, fitness exercise, laughter, applause rhythmic movements, and meditation. The purpose of this study was to test the effect of laughter yoga therapy to reduce work stress levels on military pilots of Indonesian army in Semarang, Central Java. A quasi-experimental pretest-posttest control group design was applied. Subjects comprised 10 military pilots of Indonesian army in Semarang which were compared to 10 military pilots that served as controls. Data were collected using the Work Stress Scale (26 items; $\alpha=.902)$. The t-test results showed a significant reduced work-stress level after the laughter yoga therapy was applied $(t(16.025)=-8.471 ; \mathrm{p}=.00$; $\mathrm{p}<.001)$.
\end{abstract}

Keywords: laughter yoga therapy; work stress, military pilot; Indonesian army

\begin{abstract}
Abstrak
Terapi yoga tawa adalah teknik latihan fisik yang menggabungkan teknik pernapasan yoga, latihan kebugaran fisik, tawa, tepuk tangan gerakan ritmis, dan meditasi. Tujuan dari penelitian ini adalah untuk menguji pengaruh terapi yoga tawa untuk mengurangi tingkat stres kerja pada pilot militer di Semarang, Jawa Tengah. Metode eksperimen kuasi yang diterapkan adalah pretest-posttest control group design. Subjek terdiri dari 10 pilot militer tentara Indonesia di Semarang yang dibandingkan dengan 10 pilot militer sebagai kontrol. Data dikumpulkan dengan menggunakan Skala Stres Kerja (26 item; $\alpha=0,902)$. Hasil uji t menunjukkan tingkat stres kerja berkurang signifikan setelah penerapan terapi yoga tawa $(t(16,025)=-8,471 ; \mathrm{p}=0,00 ; \mathrm{p}<0,001)$.
\end{abstract}

Kata kunci: terapi yoga tawa; stres kerja; pilot milter; tentara Indonesia

\section{PENDAHULUAN}

Pada dasarnya, istilah stres merupakan istilah yang netral, artinya stres bisa berdampak positif atau negatif. Stres merupakan suatu peluang jika stres itu menghasilkan suatu perolehan yang potensial (eustress). Namun disisi lain, stres dapat membahayakan individu karena diakibatkan oleh suatu pekerjaan yang dapat mengancam keselamatan seseorang maupun orang lain (distress). Stranks (2005) menjelaskan stres kerja adalah keadaan psikologis yang dapat menyebabkan seseorang menjadi disfungsional di dalam pekerjaannya dan merupakan hasil dari respon seseorang karena ketidakseimbangan antara beban kerja dengan kemampuannya untuk menyelesaikan pekerjaannya tersebut.

Stres kerja dapat menjadi bagian dari kehidupan individu dan organisasi. Stres kerja yang menumpuk akan merugikan tenaga kerja dan juga organisasi yang bersangkutan karena sangat berpengaruh terhadap produktivitas kerja atau performansi pekerja yang dihasilkan (Stranks, 2005). Menurut Luthans (2006), stres diartikan sebagai interaksi individu dengan lingkungan, tetapi kemudian diperinci lagi menjadi respon adaptif yang 
dihubungkan oleh perbedaan individu dan atau proses psikologi yang merupakan konsekuensi tindakan, situasi, atau kejadian eksternal (lingkungan) yang menempatkan tuntutan psikologis dan atau fisik secara berlebihan pada seseorang.

Leung, Janet \& Yee (2007) menyebutkan enam indikator stres kerja. Pertama adalah perilaku pribadi, yaitu keadaan atau aktivitas dari karyawan itu sendiri di dalam organisasi. Kedua adalah dukungan sosial, yaitu dukungan dari dalam organisasi maupun dukungan dari luar organisasi. Ketiga adalah konflik peran, yaitu kondisi di mana karyawan memikul tugas atau jabatan dan menanggung semua konsekuensinya yang berhubungan dengan pekerjaan dalam perusahaan. Keempat adalah lingkungan buruk, yaitu keadaan di sekitar organisasi terutama di dalam ruang kerja. Kelima adalah beban kerja, yaitu keadaan pekerjaan yang dibebankan kepada karyawan atau jenis pekerjaan yang harus diselesaikan tepat waktu dan yang terakhir adalah situasi rumah dan pekerjaan, yaitu kondisi antara keadaan di rumah tangga dengan keadaan yang ada di perusahaan.

Gejala stres kerja yang dialami oleh pekerja dapat dialami dalam berbagai bentuk. Cooper \& Straw (2005) membagi gejala stres kerja menjadi tiga yaitu: (1) gejala fisik, mencakup: nafas memburu, mulut dan kerongkongan kering, tangan lembab, merasa panas, otot tegang, pencernaan terganggu, diare, sembelit, letih yang tak beralasan, sakit kepala, salah urat, gelisah; (2) gejala-gejala dalam wujud perilaku, mencakup: (a) perasaan, berupa: bingung, cemas, dan sedih, jengkel, salah paham, tak berdaya, tak mampu berbuat apa-apa, gelisah, gagal, tak menarik, kehilangan semangat; (b) kesulitan dalam: berkonsentrasi, berfikir jernih, membuat keputusan dan (c) hilangnya: kreativitas, gairah dalam penampilan, minat terhadap orang lain. (3) gejala-gejala di tempat kerja, antara lain: (a) kepuasan kerja rendah, (b) kinerja yang menurun, (c) semangat dan energi hilang, (d) komunikasi tidak lancar, (e) pengambilan keputusan jelek, (f) kreativitas dan inovasi berkurang, (g) melakukan tugas-tugas yang tidak produktif. Berdasarkan beberapa pengertian tersebut dapat dikatakan bahwa stres kerja adalah ketidakmampuan seseorang dalam menyelesaikan beban atau tugas kerjanya sehingga kognitif, emosi dan perilaku akan berespon dengan tidak mampu terhadap tugas tersebut dan mempengaruhi kondisi fisiologis.

Salah satu jenis pekerjaan yang memiliki potensi stres kerja yang tinggi adalah penerbang militer (Mustopo, 2011). Para penerbang tersebut dituntut untuk dapat menyesuaikan dirinya dengan tugas pekerjaannya tersebut dengan segala konsekuensinya. Konsekuensi yang harus dihadapi oleh penerbang tersebut adalah mereka harus bisa mempelajari dan menggunakan sistem pesawat, termasuk upaya bertahan hidup bila menghadapi kegagalan sistem. Konsekuensi akan meningkat menjadi resiko stres bagi penerbang bila berkaitan dengan tujuan militer, karena selain mereka harus menyesuaikan dirinya dengan sistem penerbangan, penerbang tersebut juga dituntut untuk dapat bertahan hidup menghadapi berbagi ancaman dan risiko sesuai tugas-tugas kemiliteran. Semua ini mempunyai implikasi terhadap kondisi emosi dan perilaku penerbang militer. Misimisi operasi penerbangan militer mempunyai implikasi tuntutan tugas yang berat dan pengalaman stres yang kuat bagi penerbang dan awak pesawatnya (Mustopo, 2011). Young (2008) menjelaskan bahwa permasalahan menjadi serius bila terjadi kondisi ketidakseimbangan antara kemampuan teknis yang kurang mampu menghadapi situasi operasi dengan kemampuan mengatasi stres, maka stres yang dihadapi bisa mengakibatkan human 
errors yang bisa mencelakakan penerbang maupun awak pesawat.

Beban kerja mental yang terlalu tinggi (overload) merupakan stresor utama dalam penerbangan yang dapat memberikan dampak negatif bagi tingkat kelelahan (fatique). Seperti diketahui bahwa salah satu penyebab utama kecelakaan pesawat terbang yang disebabkan oleh manusia adalah karena faktor stres dan kelelahan (fatique) yang melanda seorang pilot. Ciriciri fatigue dapat berupa perasaan letih (feeling of tiredness) atau menurunnya kinerja (drop performance) yang apabila tidak diperhatikan dapat menjadi sumber terjadinya suatu kecelakaan pesawat terbang (Mustopo, 2011).

Hasil penelitian pada pilot penerbangan sipil menunjukkan adanya pengaruh stressor kerja terhadap gangguan mental dengan prevelansi gangguan mentalemosional $39,4 \%$. Faktor yang dominan berkaitan dengan gangguan mental emosional adalah stres kerja. Hasil penelitian lainnya juga menunjukkan bahwa responden dengan stressor kerja yang tinggi mempunyai resiko 4-6 kali lebih besar mengalami gangguan emosional dari pada responden dengan stressor kerja yang rendah (Widyahening, 2007). Selain itu, hasil penelitian pada pilot angkatan udara menunjukkan bahwa stres kerja berhubungan dengan kepuasan kerja secara keseluruhan (Bokti \& Talib, 2009). Kepuasan kerja yang tinggi akan mengurangi stres kerja dan membentuk lingkungan kerja yang positif (Fairbrother \& Warn dalam Bokti \& Talib, 2009), mendukung psychological well being, mengurangi intensi turnover dan pada akhirnya mempengaruhi intensi untuk keluar dari tempat kerja (Harrington, Bean, Pintello \& Mathews dalam Bokti \& Talib, 2009).

Berdasarkan latar belakang masalah yang telah diungkapkan di atas maka penelitian ini bertujuan untuk mengetahui pengaruh penerapan terapi yoga tawa untuk menurunkan tingkat stres kerja pada penerbang militer.

Adanya berbagai macam tuntutan dan resiko pekerjaan yang berat yang harus dihadapi oleh para penerbang militer menunjukkan adanya kebutuhan penanganan agar para penerbang militer dapat mengatasi tuntutan atau beban kerja yang tinggi yang bisa mengakibatkan stres kerja tinggi. Dampak merugikan dari stres kerja yang dialami antara lain: rendahnya produktivitas, minimnya kreativitas, berkurangnya motivasi, dan mempengaruhi dalam pengambilan keputusan (Stranks, 2005). Padahal pengambilan keputusan yang tepat serta ketenangan diri adalah salah satu faktor penting yang harus dimiliki oleh penerbang militer (Mustopo, 2011).

Penurunan stres dapat diatasi dengan cara melakukan coping. Lazarus \& Folkman (Safaria, 2006) mengemukakan bahwa coping merupakan usaha sadar individu untuk mengelola situasi yang menekan atau intensitas kejadian yang ditanggapi sebagai situasi yang menekan. Salah satu ketrampilan manajemen stres yang bisa diberikan pada penerbang militer adalah dengan emotion-focused coping. Efektivitas emotion-focused coping adalah meminimalkan pengaruh emosi melalui strategi externalizing coping yang mengurangi keluhan somatik atau agresif (O’Connor \& Campbell, 2012).

Strategi coping untuk mengatasi stres pada penerbang militer memiliki relevansi dengan performa kerjanya. Idealnya, para penerbang siap menghadapi situasi yang akut atau situasi dengan stres yang tinggi (O'Connor \& Campbell, 2012). Salah satu jenis emotion-focused coping yang bisa diterapkan untuk peningkatan kesehatan mental adalah terapi yoga tawa. Terapi 
yoga tawa merupakan terapi yang menggabungkan teknik yoga, meditasi dan tawa dalam rangka membantu individu menyelesaikan masalahnya, baik dalam bentuk gangguan fisik maupun gangguan mental. Efektivitas terapi yoga tawa untuk meningkatkan kesehatan fisik dan mental sudah semakin diakui dalam berbagai penelitian. Terapi yoga tawa menggunakan pendekatan perilaku melalui metode conditioning, yaitu dengan melatih kebiasaan seseorang untuk bisa tertawa dan bahagia. Proses tertawa pada terapi yoga tawa merupakan paduan dari peningkatan sistem saraf simpatetik dan juga penurunan kerja sistem saraf simpatetik (Hasan \& Hasan, 2009).

Berdasarkan latar belakang masalah yang diajukan di atas, maka penelitian ini akan dilaksanakan pada penerbang militer yang mengalami stres kerja. Para penerbang tersebut selanjutnya akan diberikan intervensi psikologi yaitu dengan terapi yoga tawa untuk menurunkan tingkat stres kerja yang mereka alami. Terapi yoga tawa adalah salah satu emotion-focused coping yang menggunakan teknik olah fisik. Teknik olah fisik pada terapi yoga tawa ini mengkombinasikan antara teknik yoga pernapasan, senam olah tubuh, tawa, gerakan tepuk tangan berirama dan meditasi (Kataria, 2004). Pemilihan teknik yoga dan meditasi yang digabungkan dengan tawa, karena yoga dan meditasi adalah teknik olah tubuh dan pernapasan untuk meningkatkan fleksibilitas otot-otot tubuh sehingga bisa meningkatkan imunitas tubuh.

Terapi yoga tawa diberikan dengan cara mengajak subjek untuk melakukan aktivitas tertawa dengan melibatkan perilaku dan gerakan tubuh yaitu dengan melakukan berbagai macam latihan teknik tawa untuk memunculkan perilaku tertawa yang alami. Individu akan berlatih melakukan gerakan motorik dan suara tertawa, yang akhirnya berakhir pada kondisi fisiologis (meningkatnya sistem saraf parasimpatetis dan menurunnya sistem saraf simpatetis). Beberapa penelitian terhadap terapi yoga tawa menunjukkan, bahwa terapi yoga tawa memiliki dampak psikologis dan fisiologis, terkait stres, efikasi diri, dan tekanan darah (Beckman, Regier \& Young, 2007; Chaya, Kataria \& Nagendra, 2008; Christina, 2006).

Berikut ini adalah tahapan dari penerapan kegiatan terapi yoga tawa pada penerbang militer, yang mengacu pada tahapan yang diungkap oleh Kataria (2004):

1. Sesi pengenalan, latihan peregangan, pernapasan, dan pengucapan "ho ho ha ha ha".

Pada pertemuan pertama tim fasilitator terapi yoga tawa mengenalkan diri begitu pula dengan peserta. Pada sesi perkenalan ini fasilitator menyampaikan teori dan manfaat tentang terapi yoga tawa. Kemudian dilanjutkan dengan tahap berlatih keterampilan dasar yaitu teknik pernapasan dalam (diafragma), teknik peregangan, dan latihan gerakan ritmis diafragma dengan mengucapkan "ho ho ha ha ha". Latihan pernapasan ini bertujuan agar perasaan subjek lebih rileks dan lebih sehat. Selain itu, secara instan dapat mengurangi stres dengan mengeluarkan nafas yang panjang secara perlahan (Greenberg, 2008).

2. Sesi tertawa stimulus

Pelaksanaan terapi yoga tawa selanjutnya adalah melibatkan tiga macam teknik tawa stimulus yaitu tawa yoga, tawa bermain, dan tawa berdasarkan nilai-nilai tertentu, dilatihkan secara bergantian hingga subjek penelitian dapat melakukannya sendiri. Teknik tawa yoga dikembangkan dari postur yoga untuk meningkatkan kesehatan tubuh. Teknik tawa bermain bertujuan agar subjek lebih suka bermain dan dapat mengurangi rasa malu dan takut. Sikap bermain-main juga 
membantu tawa stimulus menjadi tawa spontan. Beberapa contoh tawa bermainmain seperti tawa bantahan, tawa ponsel, tawa milkshake. Teknik tawa berdasarkan nilai yaitu teknik tawa yang dirancang sehingga melekatkan nilainilai tertentu yang dibuat ketika sedang tertawa. Hal ini untuk membantu mengembangkan nilai positif sehari-hari (Nelson, 2008). Dalam pelaksanannya, terapi yoga tawa ini menggunakan pendekatan kelompok. Hal ini dilakukan atas dasar aspek komunikasi yang terkandung pada saat tertawa. Menurut Ryff \& Singer (2000) tertawa memiliki makna interaksi positif yang dapat merekatkan antar individu. Di dalam kelompok, dapat terjadi kontak mata sehingga cara ini untuk menambah efektivitas dan menghasilkan tawa secara alamiah.

3. Yoga Meditation.

Teknik yoga meditation terdapat pada teknik penutupan akhir sesi tawa yaitu meneriakkan dua slogan dan meditasi atau yang disebut sebagai "saat teduh" dengan mengangkat kedua tangan ke atas dan memejamkan mata dalam beberapa menit (Kataria, 2004). Gerakan pada teknik penutupan ini mendasarkan kepada prinsip dasar Hasya Yoga di mana mental relaxation ini dilakukan untuk menyelaraskan antara tubuh, pikiran dan jiwa sehingga dapat menekan kecemasan atau stres yang terjadi (Kataria, 2004).

4. Berbagi perasaan dan pengalaman

Kegiatan berbagi perasaan dan pengalaman dilakukan setelah melakukan latihan terapi yoga tawa, kegiatan ini berdurasi 15 menit. Kegiatan ini dipimpin oleh fasilitator, dengan cara menanyakan kepada peserta mengenai perasaannya selama melakukan latihan hari itu. Fasilitator mengajak subjek penelitian mendiskusikan hal-hal yang ditulis peserta pada lembar pengamatan diri atau hal khusus yang terjadi selama proses terapi berlangsung.

\section{METODE}

Penelitian ini merupakan penelitian kuasi eksperimen dengan menggunakan metode untreated control group design with pretest-posttest design (Shadish, Cook \& Campbell, 2002). Variabel bebas dalam penelitian ini adalah terapi yoga tawa, sedangkan variabel tergantung adalah stres kerja.

Populasi pada penelitian ini adalah penerbang militer Angkatan Darat (LANUMAD) di Semarang, Jawa Tengah, yaitu sejumlah 95 orang. Pengambilan sampel dilakukan dengan teknik purposive sampling, dengan kriteria subjek penelitian yaitu penerbang Militer Angkatan Darat Semarang, Jawa Tengah, yang memiliki skor stres kerja yang berada dalam kategori sedang, tinggi dan tinggi sekali, memiliki masa kerja minimal 1 tahun dan telah memiliki penglaman menerbangkan pesawat militer minimal 5 kali terbang. Berdasarkan hasil screening dengan menggunakan skala stres kerja, diperoleh 20 penerbang militer yang sesuai dengan kriteria yang telah ditetapkan.

Subjek penelitian kemudian dibagi dalam dua kelompok, yaitu kelompok kontrol dan kelompok eksperimen. Kelompok eksperimen akan diberikan intervensi berupa terapi yoga tawa dan dibandingkan dengan kelompok kontrol yang tidak diberikan intervensi. Untuk melihat pengaruh penerapan terapi yoga tawa tersebut maka kelompok eksperimen diberi skala stres kerja sebelum (pretest) dan sesudah (postest) pelaksanaan terapi yoga tawa, kemudian dibandingkan dengan hasil pretest dan postest dari kelompok kontrol. Desain eksperimen dalam penelitian ini tersaji dalam Gambar 1. 


\begin{tabular}{|llll|}
\hline $\mathrm{KE}$ & $\mathrm{O} 1$ & $(\mathrm{X}) \longrightarrow \mathrm{O} 2$ \\
$\mathrm{KK}$ & $\mathrm{O} 1$ & $(-) \longrightarrow \mathrm{O} 2$
\end{tabular}

Keterangan:

KE adalah kelompok eksperimen

KK adalah kelompok kontrol

(X) adalah adanya perlakuan

(-) adalah tidak adanya perlakuan

$\mathrm{O} 1$ adalah pre test, $\mathrm{O} 2$ adalah post tes

Gambar 1

Desain eksperimen untreated Control group design with pretest-postest design

Intervensi yang diberikan dalam penelitian ini adalah dengan menerapkan terapi yoga tawa, yang diberikan pada para penerbang militer Lanumad Ahmad Yani Semarang selama 5 kali dengan durasi per terapi adalah 60 menit. Intervensi terapi yoga tawa yang diterapkan dalam penelitian ini, digambarkan dalam Tabel 1.

Alat ukur yang digunakan dalam penelitian ini adalah skala stres kerja yang disusun oleh peneliti berdasarkan dari teori Cooper dan Straw (2005). Jumlah item pada skala stres kerja adalah 26 item dengan $\alpha=0,902$. Skala ini mengukur seberapa tinggi respon stres kerja yang dialami dengan gejala sebagai berikut: (1) Gejala fisik, yaitu gejala stres yang dialami oleh pekerja yang berdampak pada fisik berupa otot tegang, nafas menjadi lebih cepat, merasa panas, nafsu makan dan pencernaan terganggu, letih yang tak beralasan, sakit kepala, gelisah. (2) Gejala perilaku, yaitu gejala stres dalam wujud perilaku yang mencakup perasaan negatif, kesulitan dalam berkonsentrasi, sulit berfikir jernih, sukar membuat keputusan, berkurangnya kreativitas, berkurangnya gairah dalam penampilan, kepuasan kerja minat terhadap orang lain., kepuasan kerja rendah, kinerja yang menurun, semangat dan energi hilang, dan komunikasi tidak lancar.
Tabel 1.

Tahapan Yoga Tawa (Kataria, 2004)

\begin{tabular}{|c|c|c|}
\hline TAHAP & $\begin{array}{l}\text { MODEL SESI } \\
\text { TAWA } 15 \\
\text { LANGKAH }\end{array}$ & $\begin{array}{c}\text { PRINSIP } \\
\text { PSIKOLOGI } \\
\text { (PATEL, 1996) }\end{array}$ \\
\hline \multirow{3}{*}{ PERSIAPAN } & Langkah 1 & \multirow{2}{*}{ Breathing (Pernapasan } \\
\hline & Langkah 2 & \\
\hline & Langkah 3 & Physical Relaxation \\
\hline \multirow{14}{*}{ INTI } & Langkah 4 & \multirow{15}{*}{ 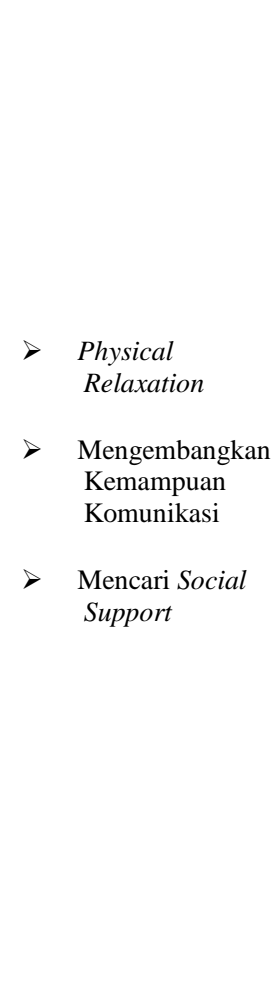 } \\
\hline & Langkah 5 & \\
\hline & Langkah 6 & \\
\hline & Langkah 7 & \\
\hline & Tawa Milk Shake & \\
\hline & Langkah 8 & \\
\hline & Langkah 9 & \\
\hline & Langkah 10 & \\
\hline & Langkah 11 & \\
\hline & Langkah 12 & \\
\hline & Langkah 13A & \\
\hline & Langkah 13B & \\
\hline & Langkah 14 & \\
\hline & Langkah 15 & \\
\hline \multirow[b]{2}{*}{ PENUTUP } & “Ayo Ngguyu” & \\
\hline & $\begin{array}{l}\text { Meneriakkan } 2 \\
\text { Slogan }\end{array}$ & $\begin{array}{c}\text { Mental } \\
\text { Relaxation, } \\
\text { meditation }\end{array}$ \\
\hline
\end{tabular}

Teknik statistik yang digunakan dalam penelitian ini adalah Independent sample ttest, dengan membandingkan (1) nilai pretest dan posttest pada kelompok eksperimen dan kontrol, dan (2) nilai posttest antara kelompok kontrol dan eksperimen.

\section{HASIL DAN PEMBAHASAN}

Subjek penelitian sebanyak 20 penerbang militer yang telah sesuai dengan kriteria subjek yang telah ditetapkan, kemudian 
ditetapkan 10 orang sebagai kelompok eksperimen dan 10 orang sebagai kelompok kontrol. Subjek yang terpilih adalah penerbang militer yang memiliki skor stres kerja yang berada dalam kategori sedang, tinggi dan tinggi sekali yang berdasarkan hasil screening skala stres kerja, memiliki masa kerja minimal 1 tahun dan telah memiliki penglaman menerbangkan pesawat militer minimal 5 kali terbang.

Subjek pada kelompok eksperimen dan kontrol diberikan skala stres kerja sebelum (pretest) dan sesudah pemberian intervensi (postest). Hasil perhitungan $t$-test pada data posttest antara kelompok eksperimen dan kelompok control menunjukkan adanya perbedaan yang signifikan ( $t=-8,471$; $d f=16,025 ; \quad \mathrm{p}=0,00 ; \mathrm{p}<0,01)$. Kelompok eksperimen memiliki tingkat stres kerja lebih rendah $(M=35,8 ; \quad S D=6,60)$ dibandingkan kelompok kontrol $(M=57,3$; $S D=4,57)$. Hal ini menjelaskan bahwa hipotesa penelitian (Ha) diterima, yaitu penerapan terapi yoga tawa dapat digunakan untuk menurunkan tingkat stres kerja pada penerbang Lanumad Ahmad Yani Semarang.

Berdasarkan hasil pengukuran skala stres kerja dan hasil diskusi selama proses pemberian terapi yoga tawa pada penerbang lanumad tersebut memang menunjukkan bahwa para penerbang tersebut perlu dibekali pendekatan yang tepat dalam mengelola stres. Peran sebagai pilot militer tidaklah mudah karena pilot merupakan penanggung jawab utama selama misi penerbangan berlangsung (Rosadi \& Mawardi, 2008). Para pilot militer tersebut dalam sesi diskusi selama proses pemberian terapi yoga tawa menyebutkan bahwa mereka memiliki tuntutan kerja dan resiko keselamatan yang bisa mengancam diri mereka ketika menerbangkan pesawat militer. Mereka menjelaskan bahwa mereka butuh penanganan segera atau kontinyu agar kondisi pikiran dan psikologis bisa tetap terjaga.

Terdapat dua pendekatan yang bisa diterapkan untuk mengelola stres kerja yaitu pendekatan individu dan pendekatan organisasi (Stranks, 2005). Pada pendekatan individual, individu dapat berusaha sendiri untuk mongurangi level stresnya. Strategi yang bersifat individual yang cukup efektif yaitu: pengelolaan waktu, latihan fisik, latihan relaksasi, dan dukungan sosial. Dengan pengelolaan waktu yang baik maka individu dapat menyelesaikan tugas dengan baik, tanpa adanya tuntutan kerja yang tergesa-gesa. Dengan latihan fisik dapat meningkatkan kondisi tubuh agar lebih prima sehingga mampu menghadapi tuntutan tugas yang berat. Selain itu untuk mengurangi stres yang dihadapi pekerja perlu dilakukan kegiatan-kegiatan santai. Dan sebagai strategi terakhir untuk mengurangi stres adalah dengan mengumpulkan sahabat, kolega, keluarga yang akan dapat memberikan dukungan dan saran-saran bagi dirinya.

Pada pendekatan organisasional, beberapa penyebab stres adalah tuntutan dari tugas dan peran serta struktur organisasi yang semuanya dikendalikan oleh manajemen, sehingga faktor-faktor itu dapat diubah. Oleh karena itu strategi-strategi yang mungkin digunakan oleh manajemen untuk mengurangi stres karyawannya adalah melalui seleksi dan penempatan, penetapan tujuan, desain ulang pekerjaan, pengambilan keputusan partisipatif, komunikasi organisasional, dan program kesejahteraan. Melalui strategi tersebut akan menyebabkan pekerja memperoleh pekerjaan yang sesuai dengan kemampuannya dan mereka bekerja untuk tujuan yang mereka inginkan serta adanya hubungan interpersonal yang sehat serta perawatan terhadap kondisi fisik dan mental. 
Berdasarkan hasil diskusi dan monitoring selama proses pemberian terapi yoga tawa, maka dapat disimpulkan bahwa terapi yoga tawa memang dapat diterapkan pada lingkungan militer karena para penerbang diajak segera untuk melepaskan ketegangan-ketegangan emosi dengan latihan atau gerakan yang menyenangkan sehingga kondisi fisiknya akan mengalami kondisi yang sehat dan prima sehingga bisa menujang selama proses menjalankan tugasnya sebagai pilot militer.

Penerapan terapi yoga tawa termasuk penanganan stres kerja secara individual (personal wellness programs), yang bersumber pada teknik emotion-focused coping. Emotion-focused coping adalah strategi yang bertujuan untuk mengendalikan respons emosi terhadap situasi menekan melalui perilaku dan mengubah kognisi. Individu cenderung menggunakan strategi ini pada saat individu tersebut meyakini bahwa tidak ada yang dapat diperbuat untuk mengubah situasi (Chamberlain \& Lyons, 2006). Emotionfocused coping dilakukan dengan mengendalikan berbagai reaksi baik jasmaniah, emosional, maupun bentukbentuk mekanisme pertahanan diri.

Berdasarkan hasil evaluasi dengan para penerbang militer setelah penerapan terapi yoga tawa bisa memberikan dampak yang positif karena: 1.) Variasi gerakan terapi yoga tawa yang menyenangkan yaitu adanya berbagai gerakan pada masingmasing tahapan yoga tawa, di mana sekelompok orang melakukan kegiatan tertawa sebagai olahraga berdasarkan gerakan yoga, disusul dengan sikap bermain-main yang membantu para peserta untuk tertawa secara spontan. Jenis latihan tawa seperti ini bisa dilakukan di luar, seperti di taman umum atau pantai, atau di dalam ruangan. Latihan ini dilakukan sambil berdiri dan di dalam sesi terdapat banyak gerakan, interaksi dan kontak mata.
2.) Adanya fase meditasi tawa, di mana subjek tidak harus berusaha untuk tertawa, namun menghasilkan tawa dalam kondisi tenang dan berasal dari jiwa. Meditasi tawa ini dapat dilakukan di luar ruangan, namun membutuhkan keheningan dan kosentrasi. Oleh karena itu, meditasi tawa bisa dilakukan di dalam ruangan atau ditempat alam, sambil duduk tenang dan berbaring telentang dengan mata tertutup.

\section{KESIMPULAN}

Berdasarkan hasil analisis data penelitian, dapat disimpulkan bahwa ada perbedaan stres kerja penerbang militer sebelum dan sesudah mengikuti terapi yoga tawa, yakni rerata stres kerja setelah mengikuti terapi lebih rendah $(t=-8,471 ; d f=16,025 ; \mathrm{p}=0,00$; $\mathrm{p}<0,01)$. Dengan demikian terapi yoga tawa efektif untuk menurunkan tingkat stres pada penerbang militer. Efektivitas ini dapat diuji lebih jauh dengan menerapkan terapi yoga tawa sebagai program yang diberikan secara berkelanjutan dalam bentuk klub atau kelompok tawa dan dilakukan pengukuran ulang setelah berjalan 6-12 bulan. Berdasarkan penelitian yang telah dilakukan, maka saran yang diajukan dari penelitian ini adalah terapi yoga tawa dapat diberikan untuk menangani masalah psikologis yang dialami oleh para penerbang militer, sehingga dapat dijadikan sebagai contoh program untuk dilakukan secara berkala sebagai upaya preventif dan promotif dalam meningkatkan kesejahteraan psikologis para penerbang militer. Selain itu, terapi yoga tawa ini diharapkan dapat menjadi sarana penerbang militer untuk mengungkapkan segala perasaan (express feeling), bisa tertawa dan bahagia, meningkatkan motivasi dan semangat, serta kemampuan berkomunikasi dan bersosialisasi. 


\section{DAFTAR PUSTAKA}

Beckman, H., Regier, N., \& Young, J. (2007). Effect of workplace laughter groups on personal efficacy beliefs. The Journal of Primary Prevention, 28, 167-182.

Chaya, M. S., Kataria, M., \& Nagendra, H.R. (2008). The effect of hearty extended unconditional (heu) laughter using laughter yoga techniques on physiological, psychological, and immunological parameters in the workplace: A randomized control trial. Proceeding of the 23rd Scientific Meeting of the American Society of Hypertension. New Orlean, USA

Christina, S. (2006). Pengaruh terapi tawa terhadap stress pada usia lanjut. Skripsi. (Tidak dipublikasikan). Fakultas Psikologi Universitas Surabaya.

Chamberlain, K., \& Lyons, A. (2006). Health Psychology: Cambridge: Cambridge University Press.

Cooper, C., \& Straw, A. (2005). Stres manajemen sukses dalam sepekan. Jakarta: Kesaint Blanc.

Greenberg, J. S. (2008). Comprehensive stress management 10th ed. New York: McGraw-hill.

Hasan, H., \& Hasan, T.F. (2009). Laugh yourself into healthier person: a cross cultural analysis of the effect of varying level of laughter on health. International Journal of Medical Sciences, 6(4), 200-211.

Kataria, M. (2004). Laugh for no reason (terapi tawa). Jakarta: PT Gramedia Pustaka Utama.
Leung, M., Janet, S. \& Yee, S.C. (2007). Adjusting stressors - job-demand stress in preventing rustout/ burnout in estimators. Journal Surveying and Built Environment. 18 (1), 1726.

Luthans, F. (2006). Organizational behavior 9th ed. New York: McGraw Hill.

Bokti, N. L. M., \& Talib, M. (2009). A preliminary study on occupational stress and job satisfaction among male navy personnel at a naval base in lumut malaysia. The Journal of International Social Research, 2 (9), 176-189.

Mustopo, W. I. (2011). Keselamatan penerbangan dan aspek psikologis "fatigue", Jurnal Psikobuana, 3(2), 126-134.

Nelson, J. K. (2008). Laugh and the world laughs with you: An attachment perspective on the meaning of laughter in psychotherapy. Clinical Social Work Journal, 36, 41-49.

O’Connor, P., \& Campbell, J. (2012). An evaluation of the effectiveness of the crew resource management programme in naval aviation. Int. $J$. Human Factors and Ergonomics, 1(1), 21-40.

Rosadi, H. \& Mawardi, D. (2008). Fasten your seat belt. Jakarta: Elex Media Komputindo.

Ryff, C. D., \& Singer, B. (2000). Biopsychosocial challenges of the new millennium. Psychotherapy and Psychosomatics, 69, 170-177. doi:10.1159/000012390.

Stranks, J. (2005). Stress at work, management and prevention. Burlington : Elsevier. 
Safaria, T. (2006). Stres ditinjau dari active coping, avoidance coping dan negative coping. Jurnal Humanitas, 3(2), 87-93.

Shadish, C., \& Campbell. (2002). Experimental and quasi experimental design for general causal inference. USA: Houghton Mifflin Company.

Widyahening, I. S. (2007). High level of work stressors increase the risk of mental-emotinal disturbances among airline pilots. Media Journal of Indonesia, 16 (2), 117-121.

Young, J. A. (2008). The effects of lifestress on pilot performance. California: Ames Research Center, Moffett Field. 